\title{
CONNECTING WORLD HERITAGE NOMINATIONS AND MONITORING WITH THE SUPPORT OF THE SILK ROADS CULTURAL HERITAGE RESOURCE INFORMATION SYSTEM
}

\author{
O. Vileikis ${ }^{a^{*},}$ B. Dumont ${ }^{b}$, E. Serruys ${ }^{c}$, K. Van Balen ${ }^{a}$, V.Tigny $^{b}$, P. De Maeyer ${ }^{c}$ \\ ${ }^{a}$ Raymond Lemaire International Centre for Conservation (RLICC), University of Leuven (KU Leuven), \\ Kasteelpark Arenberg 1 - B 2431, 3001 Heverlee, Belgium. \\ ona.vileikis@asro.kuleuven.be \\ ${ }^{\mathrm{b}}$ GIM nv, Researchpark Haasrode 1505, Interleuvenlaan 5, 3001 Heverlee, Belgium. \\ c Ghent University, Department of Geography, Krijgslaan 281, S8 B-9000 Gent, Belgium
}

\section{CIPA Heritage Documentation}

KEY WORDS: World Heritage, Information Management Systems, Silk Roads, Digital Documentation, Monitoring, Periodic Reporting

\begin{abstract}
:
Serial transnational World Heritage nominations are challenging the way cultural heritage has been managed and evaluated in the past. Serial transnational World Heritage nominations are unique in that they consist of multiple sites listed as one property, distributed in different countries, involving a large diversity of stakeholders in the process. As a result, there is a need for precise baseline information for monitoring, reporting and decision making. This type of nomination requires different methodologies and tools to improve the monitoring cycle from the beginning of the nomination towards the periodic reporting. The case study of the Silk Roads Cultural Heritage Resource Information System (CHRIS) illustrates the use of a Geographical Content Management System (Geo-CMS) supporting the serial transnational World Heritage nomination and the monitoring of the Silk Roads in the five Central Asian countries. The Silk Roads CHRIS is an initiative supported by UNESCO World Heritage Centre (WHC) and the Belgian Federal Science Policy Office (BELSPO), and developed by a consortium headed by the Raymond Lemaire International Centre for Conservation (RLICC) at the KULeuven. The Silk Roads CHRIS has been successfully assisting in the preparation of the nomination dossiers of the Republics of Kazakhstan, Tajikistan and Uzbekistan and will be used as a tool for monitoring tool in the Central Asian countries.
\end{abstract}

\section{INTRODUCTION}

The inscription of serial transnational properties on the World Heritage List has been steadily increasing in recent years. These properties include two or more component parts, spread over different State Parties (UNESCO 2012a, para.137), that might utilize and involve different working methodologies, languages, types of data, stakeholders and management frameworks. These differences become more pronounced when it comes to evaluating and reporting on the overall performance of the property related to its Outstanding Universal Values (OUV) and State of Conservation (SoC).

Fundamental to the management of these properties is vigilant documentation and monitoring, two main components of the management cycle. Resource Manuals published by UNESCO and the Advisory Bodies serve as guidelines for the preparation of World Heritage nominations but there are no specific ones for serial nominations (UNESCO et al. 2011). Compared to single nominations, managing proper documentation and monitoring is a greater challenge for serial transnational nominations. As a result, the use of advanced management tools is essential.

This paper focuses on the Silk Roads Cultural Heritage Resource Information System (CHRIS), a Geospatial Content Management System (GeoCMS) developed to support the serial transnational World Heritage nomination and monitoring of the Silk Roads in the five Central Asian countries of Kazakhstan, Tajikistan, Turkmenistan, Kyrgyzstan and Uzbekistan. We will describe the architecture of the system, its main features, its expediency in the preparation of the nomination dossier and its use during monitoring and reporting.

\section{SERIAL TRANSNATIONAL WORLD HERITAGE PROPERTIES}

Serial transnational World Heritage properties should not be managed the same as single properties. They require more complex and joint data repositories and good baseline information of the component parts that should be linked to and presented as one property. Currently, there are 745 cultural World Heritage properties inscribed, of which 29\% are serial properties; almost a third of all cultural properties (UNESCO WHC 2013). At a serial transnational level, there currently exists six cultural properties, namely, Jesuit Missions of the Guaranis (1983/1984), Frontiers of the Roman Empire (1987, extensions: 2005, 2008), Struve Geodetic Arc (2005), Belfries of Belgium and France (1999/2005), Stone Circles of Senegambia (2006) and Prehistoric Pile Dwellings around the Alps (2011), while others are under preparation or evaluation such as the Vikings, the Qhapaq Ñan and the Silk Roads in China and Central Asia (Swiss Federal Office of Culture et al. 2010).

\footnotetext{
Corresponding author.
} 


\subsection{Documentation and inventories}

In most cases the State Parties (SP) apply their own national inventories or a website where information about the component parts is stored, sometimes linked to a GIS showing buffers and boundaries. However, to our knowledge none of the cultural serial transnational nominations make use of a management or monitoring tool specifically created for the entire World Heritage property. For example, the component parts of the Frontiers of the Roman Empire can be accessed through two different platforms. First, in the United Kingdom, the component parts can be accessed through the OASIS database (OASIS UK), which links different archaeological databases in England and Scotland. Second, the Upper Germanic-Rhaetian boundary wall (Limes) in Germany can be accessed through the LimesDatenbank a database with restricted access (DKL). Additionally, there is a multilingual FRE-thesaurus provided by the Austrian partner and containing the translations of the most frequently used terms for architectural monuments along the Roman Frontiers (EU Culture 2000 FRE Project).

Another example is the Belfries, including 56 component parts in France and Belgium (Wallonia and Flanders). From the French side, there is one official website including information about all Belfries (in French) (Association Beffrois \& Patrimoine). In Belgium, the information is provided by two regional inventories. Under the GD04 (Direction Générale Opérationnelle de L’aménagement du Territoire, du Logement, du Patrimoine et de L'énergie), Wallonia counts with an inventory including the 'Biens exceptionnels' (Outstanding properties), in this case the Belfries. The inventory lists basic information of the properties linked to the cadastral map, old maps or Google Maps (SPW-DG04). Flanders has an online inventory "Inventaris" administrated by the Flemish agency for Immovable Heritage containing over 80000 items or relics linked to Open Street Map (VIOE). There is no joint monitoring. In Flanders for example, Monument Watch Flanders, a non-profit agency, supported by the Flemish government, specializes in the monitoring and maintenance of immovable heritage. Of the 26 component parts, just the Belfry in Gent is registered in the database, however there is no information about subsidies or maintenance plans (Monumentenwacht 2013).

Finally, in the five Central Asian countries nominating the Silk Roads, there is a systematic methodology of national inventories. The sites are documented based on the monument passport inventory form. For instance, based on these forms, Kazakhstan publishes every year a series of books about each of its regions. Every year, two updated books are prepared, founded on administrative territorial division. In Uzbekistan, the forms are available at the Board of Monuments or the regional offices, but these passports are not accessible online and most of the maps are still in hard copies. Thus, the Silk Roads CHRIS has turned out a useful tool to set up the right baseline information for the preparation of this nomination, it has helped the countries to standardize the data available and set up a methodology to record new information in a way that it could be used for monitoring and reporting of the properties.

\subsection{Monitoring and Reporting on cultural World Heritage}

Following 29 Article of the World Heritage Convention (UNESCO 1972), State Parties should report on the status of the implementation of the Convention. This mechanism serves as a control to know whether the values, for which the properties were inscribed, have been maintained over time and what kind of measures are to be taken if there are management issues to be solved. Within the established World Heritage monitoring cycle, SP are requested every six years to prepare the Periodic Reporting (PR). This includes two sections, the first aiming at evaluating the commitment of the SP in the application of the World Heritage Convention and the second the SoC of each property (UNESCO 2012a, para.206). In serial transnational properties $\mathrm{PR}$ is also relevant to promote exchange of information, involvement of stakeholders and regionaltransnational cooperation. However, there is no specific form for serial properties within the PR, which makes it complex for the SP to execute the periodic reporting.

After the first cycle experience, and the reflection year on the WH PR, the second PR cycle started in 2008 with the Arab States and will come to an end in 2015 with Europe and North America. In the case of Asia and Pacific (2011), the report revealed the situation at the time for a large number of WH properties in $41 \mathrm{SP}$. This exercise showed that in the field of documentation there is still much to be improved. For instance, as part of the retrospective inventory of 96 properties, 30 met the requirements of cartographic information, and although there are no specific standards of inventories, figures show that $65.9 \%$ of cultural properties count with complete or well advanced national inventories. As for monitoring it was highlighted that there is still a need to put in place the right key indicators to assess the OUV over time. Thus, regarding monitoring there does not exist examples or results at a cultural serial transnational level, as there are no such properties in the region. There are, however, two such properties under preparation, the Silk Roads being one of them (UNESCO 2012b).

The PR is a control needed for the SP to stop and reflect on the the positive aspects of their properties as well as on challenges these are facing. Although continuous monitoring activities to support periodic reporting seem a logical step, it is not implemented in most of the cases. Mechanisms proposed such as the "reinforced monitoring"i have also shown that the current WH monitoring system is at times not enough, especially when it comes to taking decisions on the future of sites under the List in Danger. Thus, new methodologies and tools in documentation, such as the Silk Roads CHRIS, should be implemented specially in times when integration and monitoring of large volumes and types of information at a transnational level are becoming a relevant issue.

\section{THE SILK ROADS CULTURAL HERITAGE RESOURCE INFORMATION SYSTEM (CHRIS)}

The Silk Roads CHRIS is an initiative set up to support the serial transnational nomination of the Silk Roads in the five Central Asian countries and its future monitoring. Supported by the World Heritage Centre, and the Belgian Federal 
Science Policy Office (BELSPO), it is being developed by a Belgian consortium headed by the Raymond Lemaire International Centre for Conservation (RLICC), K.U.Leuven. After several consultations and meetings ${ }^{\text {ii }}$ that took place in the last seven years, in February 2013, the five Central Asian SP together with China submitted the first phase of the nomination for evaluation. The nomination concept, based on the system of corridors proposed during the Ashgabat meeting and approved by the 12 State Parties involved in the nomination, faced major challenges. First, in the recording, documentation and integration of large volume of information and second in the development of a accurate monitoring tool and management approach for the variety of monuments and sites and their further reporting. Therefore, the Silk Roads CHRIS was proposed as an optimal tool for both, the compilation of the nomination dossier and a later monitoring at a transnational level.

Silk Roads CHRIS is a value-based approach based on the PRECOMOS methodology on Preventive Conservation to Cultural Heritage (RLICC 2011). It has two sections, the nomination dossier and the monitoring tool. As shown in Figure 1, based on the Operational Guidelines (OG) (UNESCO 2012a Annex 5) a nomination dossier for editing, viewing and reviewing was designed and implemented. It includes geographical information as well as information available for each corridor and its component parts to be nominated. Moreover, it provides access to the monitoring tool. Various types of data can be added to the Silk Roads CHRIS such as images, texts, or 3D models. The nomination dossier is the baseline information for later monitoring and reporting. The more precise the information, the easier it will be for the State Parties to manage the changes in time.

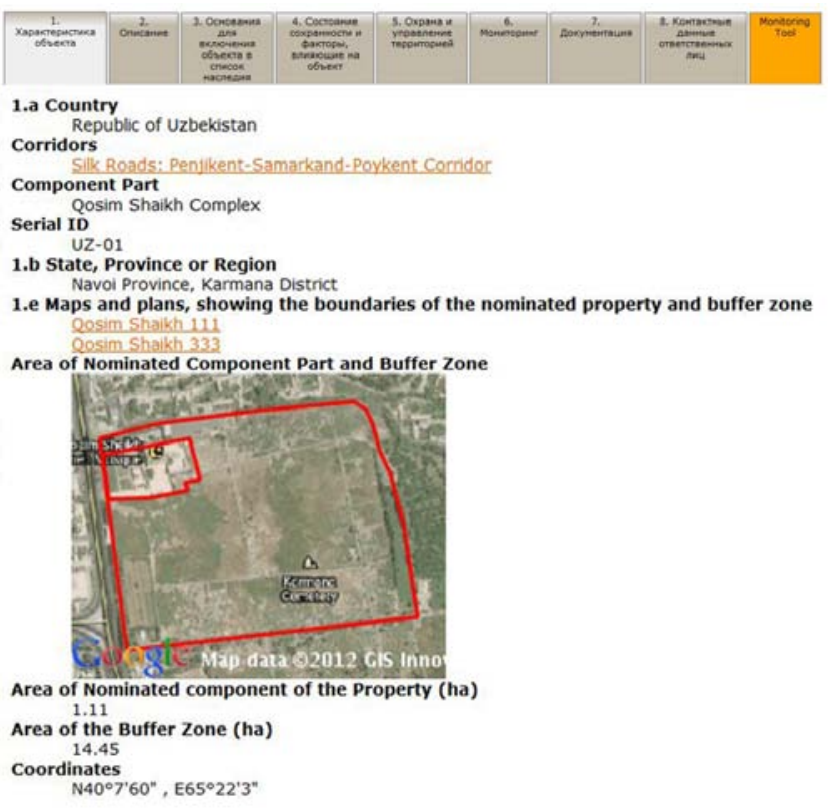

Figure 1: Nomination Dossier (C) Silk Roads CHRIS.

The aim of the monitoring tool is to assist the SP in the monitoring of the corridors and their sites in order to identify threats affecting the OUV and be able to prioritize issues that need to be monitored and tackled by the management strategies. The monitoring tool contains a risk and a management assessment tool, where information on the corridors and component parts included in the nomination dossier are linked to the OUV and other local values. Subsequently, the risk assessment tool will be explained. It has been proposed based on the Petra Risk Management case study with some variations (Paolini et al. 2012). In the Silk Roads CHRIS, threats or disturbances have been grouped based on the factors affecting the property of the nomination dossier (UNESCO 2012a Annex 5 (4.b)) and the Section II form of the Periodic Reporting. From these threats or disturbances a selection of those that are applicable to the Silk Roads was made. These threats or disturbances could be then linked to their possible cause based on 10 Agents of Deterioration (Waller 1995) (See Figure 2).

\begin{tabular}{|c|c|}
\hline Group 1: Development Pressures & \\
\hline \multicolumn{2}{|l|}{ Urban and Infrastructure Development } \\
\hline \multicolumn{2}{|l|}{1101 encroachment } \\
\hline 1102 urban high rise... & 3101 earthquake \\
\hline \multicolumn{2}{|l|}{ Physical resource extraction } \\
\hline \multicolumn{2}{|l|}{1201 mining } \\
\hline \multicolumn{2}{|r|}{3201 temperature change } \\
\hline \multicolumn{2}{|l|}{ Tourism } \\
\hline \multirow{2}{*}{$\begin{array}{l}1301 \text { visitor accommodation and } \\
\text { associated infrastructure } \\
1302 \text { visitor's facilities... }\end{array}$} & Group 4: Management Pressures \\
\hline & Management activities \\
\hline & 4201 inappropriate maintenance... \\
\hline \multicolumn{2}{|l|}{ Group 2: Environmental Pressures } \\
\hline \multirow{2}{*}{$\begin{array}{l}\text { Local conditions affecting physical } \\
\text { fabric }\end{array}$} & Group 5: Human Activity Pressures \\
\hline & Interaction with society \\
\hline & $\begin{array}{l}5101 \text { inappropriate contemporary use } \\
5102 \text { change of uses }\end{array}$ \\
\hline $\begin{array}{l}2102 \text { temperature variation... } \\
\text { Invasive or hyper-abundant species }\end{array}$ & Unfavorable Human Activities \\
\hline \multicolumn{2}{|r|}{5201 graffiti and tagging } \\
\hline \multicolumn{2}{|l|}{ Pollution } \\
\hline \multirow{2}{*}{$\begin{array}{l}2301 \text { moist spots } \\
2302 \text { surface deposition... }\end{array}$} & Group 6: Other Pressures \\
\hline & 6101 animal (non-domestic) impact \\
\hline \multicolumn{2}{|l|}{ Biological resource use/modification } \\
\hline 2401 grazing. & \\
\hline
\end{tabular}

\begin{tabular}{|l|}
\hline Agents of Deterioration \\
\hline AG01 Fire \\
AG02 Water \\
AG03 Climate \\
AG04 Physical Forces \\
AG05 Electromagnet Waves \\
AG06 Biological Agents \\
AG07 Contaminants \\
AG08 Dissociation \\
AG09 (in)direct impact from human activities \\
and human development on the fabric \\
AG10 Risk for the users related to the use \\
(which use) of the cultural heritage fabric \\
\hline
\end{tabular}

Figure 2: Groups of threats linked to the Agents of Deterioration (C) author

Each threat is linked to an attribute belonging to specific criteria containing the OUV. These attributes were defined based on recorded semi-structured interviews, oral histories, focus groups with experts and primary literature, and assessed using the Nara Grid (Van Balen 2008). Following the methodology, qualitative and quantitative risk assessment can be carried out and mitigation strategies can be proposed. As depicted in Figure 3 and Figure 4, the data is added to each of the component parts and an overview of each risk is shown at the corridor level. The first risk assessment form will help to identify the factors affecting the property serving later as baseline information to set up objectives and strategies for the management and monitoring of the property. 


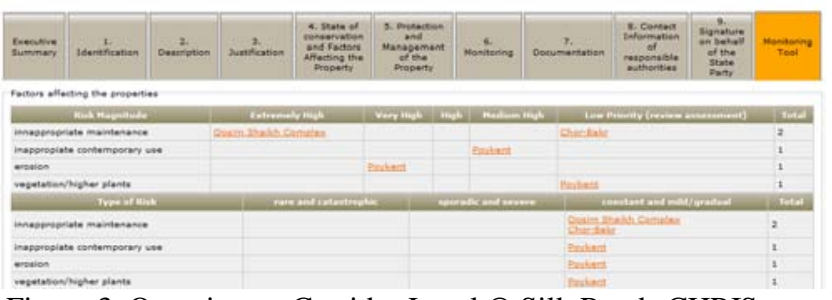

Figure 3: Overview at Corridor Level (C) Silk Roads CHRIS.

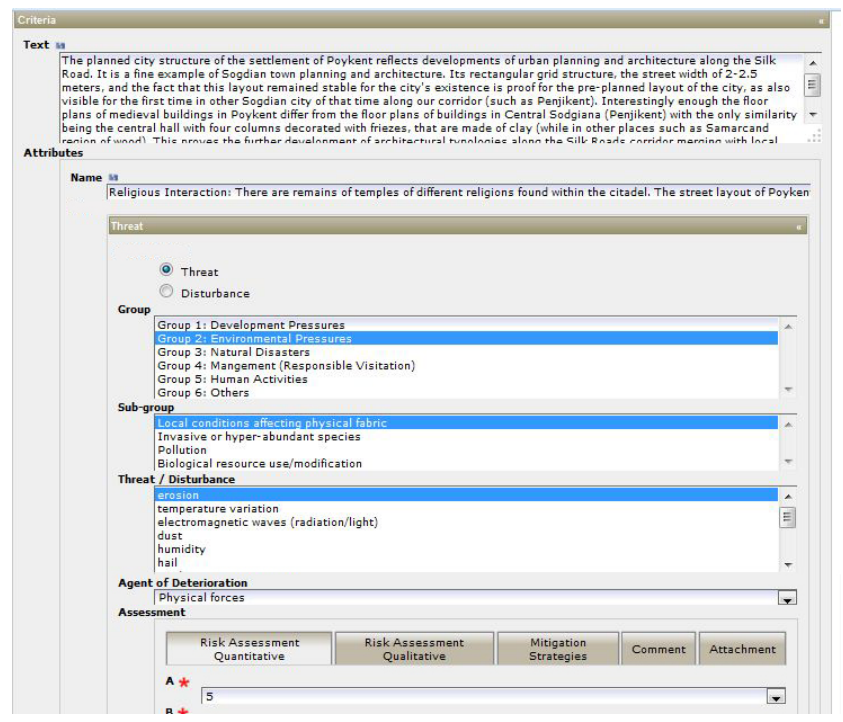

Figure 4: Risks Assessment (C Silk Roads CHRIS.

\subsection{The system architecture}

The Silk Roads CHRIS is a GeoCMS. In contrast to a desktop GIS, the Silk Roads CHRIS is a light weighted online GIS, not meant for heavy spatial analysis which are typically run in GIS desktop applications. The Silk Road CHRIS does allow you to perform basic spatial analysis editing tasks, changing geometry, to fill or change attributes and adapt the data model if needed. It allows on-line access to different groups of users and has the capability to manage, search and publish different types of data but as a web application.

The Silk Roads CHRIS is an example of a spatial data infrastructure (SDI), using four different components: a PostGIS database, GeoServer as a data server, Apache Tomcat as an application server and a web based GeoCMS. (1) The GeoCMS is built with J2EE technologies and Java standards. The Silk Roads CHRIS is fully mainly designed for the preparation of the nomination dossier, but the information is also related to a monitoring tool and a data repository. (2) The geospatial database is a centralized database, containing geographical information, and the configuration data of the GeoCMS. The open source PostGreSQL database together with a PostGIS extension is used. It is a well-known and stable open source database management system with a very broad user and developer's community. (3) In combination with the PostGreSQL/PostGIS, GeoServer, an open source Geographic Web Service product, was used to serve geographic vector and raster data sets via the OGC Web Map Service and Web Feature Service protocol. One of the strong points of GeoServer is its easy-to-use web-based configuration tool.

\subsection{Key features}

Based on the system requirement analysis, a set of key features has been implemented in the Silk Roads CHRIS. This set includes: easy use and online access, multilingualism, open standards, querying, different scales, background maps, data and bibliographic repository, and tracking and exporting. These features are explained below:

The Silk Roads CHRIS is a user friendly system taking into account that a often many end-users do not have expertise in ICT or GIS. The State Parties are guided online through the section of the nomination dossier, as well as the monitoring tool with no browser plug-in or applets. The whole content management system, e.g. the nomination dossier, could be presented, stored and exported in Russian and English and other languages could be added if necessary. All software commands as well as menus, tooltips and fields are grouped in a message bundle or datamodel that can be translated in batch.

Moreover, the Silk Roads CHRIS provides an open, interoperable system, based on Open Standards. These standards are focused on data models and formats including metadata, and spatial web services. Standards facilitate data exchange and querying. All source geodata can be searched upon, e.g. dropdown list boxes, free text searches, datum controls, as well as default values and configured for any kind of vector data. This function supports the user to easier find results within the whole repository with the use of keywords such as date, place, geographical coordinates or author.

Levels of Scale and details: The system has three different levels of scale: the Silk Roads, the Corridors and Component Parts, proving access to different information Because of the interoperable character of the system, more corridors and component parts could be added any time.

The detail of recording has been defined by the requirements of the OG (UNESCO 2012a). For the nomination dossier a reconnaissance or preliminary level of recording at a component part level is needed, including photographs, sketches and measured records of plans and specific details. However, for the monitoring of the site detailed recording is needed. The Silk Roads CHRIS has been populated and shared by the State Parties, showing the capability of the system. This data was first collected in the field, and then prepared to create the different layers and the corresponding symbology, Styled Layer Descriptors. Later, the layers were uploaded to the CHRIS configured by GeoServer.

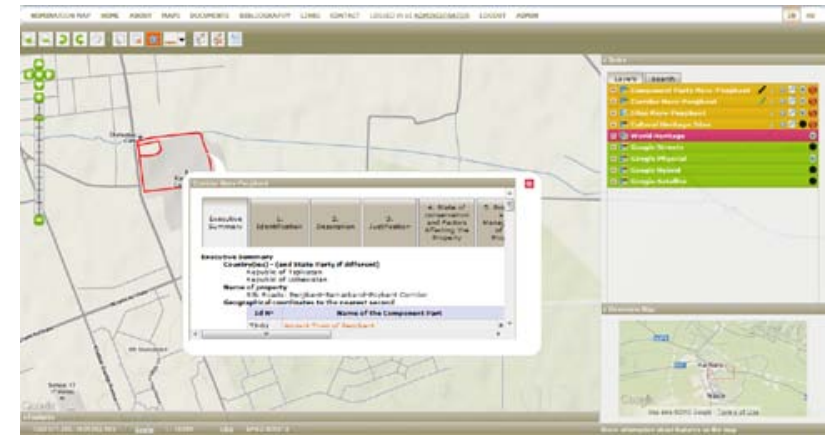

Figure 5: Geographical Information (CSilk Roads CHRIS. 
Background Maps: The Google Maps Application Programming Interface (API) was used to implement satellite and map background layers in the Silk Roads CHRIS demonstrator to provide rich contextual information of relevance to the stakeholders (See Figure 5). Google Maps operates with the spherical Mercator projection system, thus, all datasets WGS84 coordinates are reprojected by GeoServer.

To support the preparation of the nomination dossier, as shown in Figure 6, the GeoCMS permits creating or reshaping the boundaries and buffer zones of the component parts based on the Google Maps background data. Both areas are calculated, based on this geometry, by using the getArea function from the Geometry Class of the Java Topology Suite (JTS) and automatically displayed in the corridor data model table together with the coordinates of the centre point. These coordinates are calculated using the getCentroid function of the Geometry Class of the JTS.

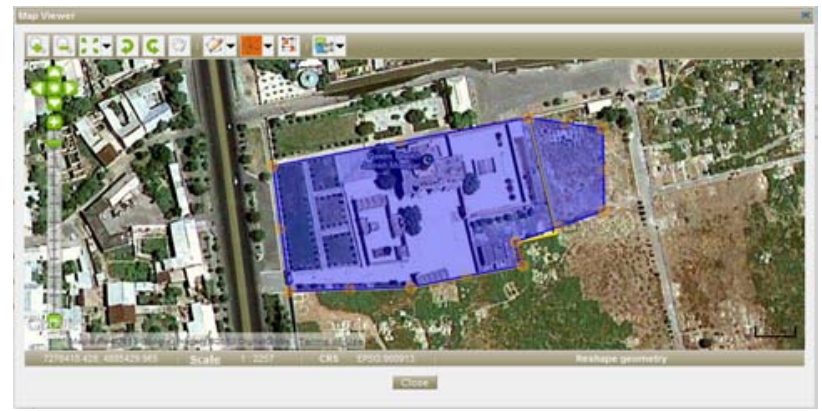

Figure 6: Component Part Level @ Silk Roads CHRIS.

Data taken in the field with GPS can also be exported. During the training sessions in Uzbekistan the boundaries and buffer zones of nine component parts were drawn in the Silk Roads CHRIS on the background data, then the maps were printed out and points were verified in the field with a GPS 62s Garmin - WGS 84 datum, and finally exported to the system. When the background data was not clear enough, raster data was added to the GeoCMS such as scanned topographical maps provided by the SP or WorldView-2 satellite images with an accuracy of $0.5 \mathrm{~m}$ at a component part. Raster data was georeferenced by converting the row/column locations to their actual real-world coordinates (WGS84). In the future, other raster images can be added to track the changes in time via remote sensing. The boundaries mapped in the CHRIS are legally enforced by each State Party and submitted for the World Heritage nomination.

Repository: The repository contains two parts bibliography and documents. All information has its own metadata and is stored in the PostgreSQL/PostGIS database. The bibliography is populated with data collected by the ICOMOS Silk Roads Thematic Study as well as prepared by each SP (Williams 2011). It has open access to the general public. It permits the user to search for bibliography, add a new item or download the result list. Moreover, this items could be linked to the section 7 of the nomination dossier. The documents are different type of data that could be linked either to the nomination dossier or the monitoring tool. This data could be reference documents such as charts, laws or policies, corresponding to section 5 of the nomination dossier and the management assessment tool, as well as images (photos, plans, or sketches), 3D models or videos.

Following the methodology presented in Vileikis et al (2012) visual documentation of the condition of the sites and damages as well as of the boundaries was carried out with a Camera Nikon D5100 and each point was marked in the GPS 62s Garmin with WGS 84 datum as shown in Figure 7. Panorama photos were later stitched with PTGui stitch software. A selection of five photos per component part was linked to the section 2 and 4 of the nomination dossier. All photos contain metadata, e.g. geographical coordinates, author, institution or contact details that was automatically linked to each one of the photos added to the dossier and the copyrights table included in the section 8 Documentation. Any changes made in the metadata were always automatically changed in the dossier. All the additional photos were also uploaded to the system, and could be added to the risk assessment monitoring form to serve as baseline information and later track and compare in time the SoC and damages of the sites.

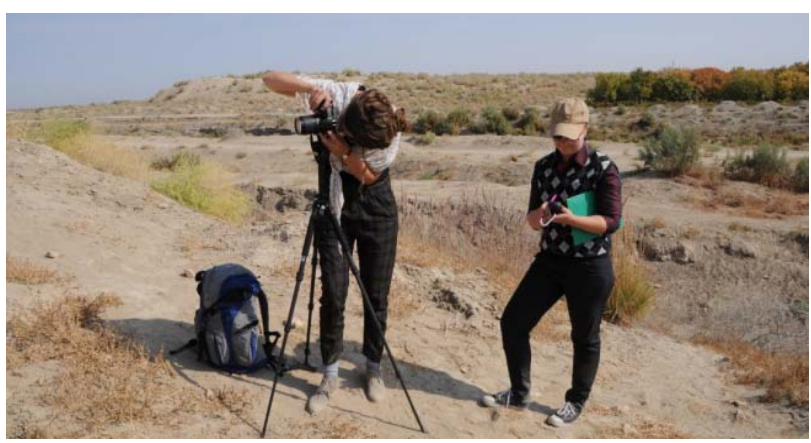

Figure 7: Team carrying out visual documentation and delineation of boundaries (C) Ona Vileikis

Tracking and exporting: The users can track and print in PDF the information added to the CHRIS as part of the nomination dossier, to verify and control the nomination process or the monitoring tool, e.g. risk assessment form. Moreover, geographical vector data can be exported to Google earth, ESRI Shapefile, or other formats. The whole nomination dossier of the "Silk Roads: PenjikentSamarkand-Poykent Corridor” (Uzbekistan and Tajikistan) was printed as final version in PDF and could be remotely accessed if desired (See Figure 8).

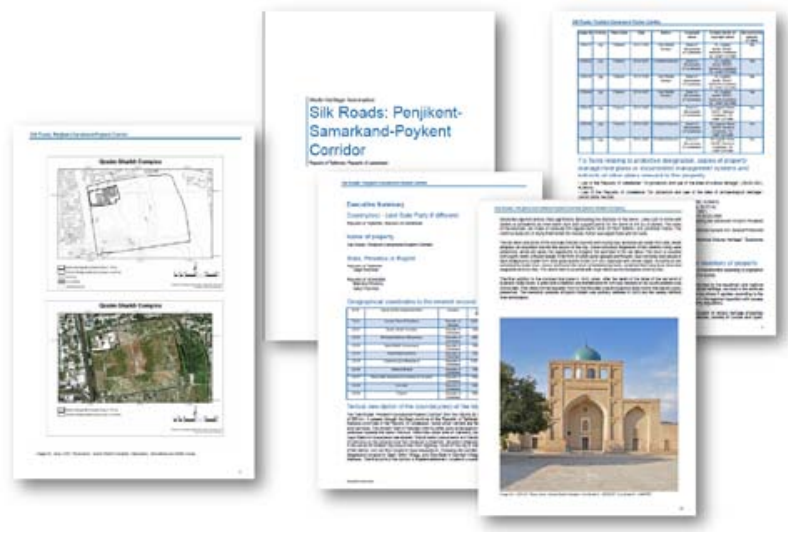

Figure 8: Nomination dossier. (C) Silk Roads CHRIS. 


\section{CONCLUSION AND FUTURE OUTLOOK}

The Silk Roads CHRIS has been a successful tool for the preparation of the nomination dossier of serial transnational World Heritage properties envisioning it as baseline information for the monitoring and later periodic reporting of the sites. Tajikistan, Uzbekistan and Kazakhstan adopted the system for the preparation of the nomination dossier. The application of GeoCMS in cultural heritage has changed methodologies in these countries where information is not all the time digitally available but where there is still a need to share it.

The experience showed that the system must not come alone; a clear methodology has to be linked and followed along the process. The preparation of a value-based assessment is the foundation of the whole monitoring, as these values are the ones we would like to protect and track along the way. Further training in management and monitoring methodologies are necessary.

Because of its open architecture, the Silk Roads CHRIS could be open to new modules related to World Heritage and the management of the properties such as tourism, archaeology, resources and so on. The advantage of being an online system could prove valuable to Advisory Bodies and even the World Heritage Committee to review nomination processes and monitor further development once the properties have been listed.

\section{ACKNOWLEDGMENTS}

The authors wish to thank all State Parties participating in the Silk Roads CHRIS project. We would like to acknowledge the support of BELSPO, the UNESCO WHC,UNESCO Offices in Almaty and Tashkent and the UNESCO National Commissions in Central Asia. In addition, we would like to thank Prof. Tim Williams, University College London, Institute of Archaeology for his continuous advice.

\section{REFERENCES}

Association Beffrois \& Patrimoine, Beffrois de France. Beffrois et Patrimoine. Available at: http://www.beffrois.com [Accessed April 8, 2013].

Van Balen, Koenraad, 2008. The Nara Grid: An Evaluation Scheme Based on the Nara Document on Authenticity. APT Bulletin, 39(2/3), pp.39-45.

DKL, Limes-Datenbank. Available at: http://www.limesdatenbank.de/ [Accessed April 8, 2013].

EU Culture 2000 FRE Project, The Multilingual FREThesaurus. Available at: http://www.limesoesterreich.at/thesaurus/123 [Accessed September 4, 2011].

Monumentenwacht, 2013. Available at: http://www.monumentenwacht.be/ [Accessed April 8, 2013].

OASIS UK, The OASIS Project. Online AccesS to the Index of archaeological investigations. Available at: http://oasis.ac.uk/ [Accessed February 17, 2013].
Paolini, A. et al., 2012. Risk Management at Heritage Sites: a case study of the Petra World Heritage Site, Amman: UNESCO and KU Leuven.

RLICC, 2011. Precomos - Preventive Conservation, Maintenance and Monitoring of Monuments and Sites. Available at: http://precomos.org [Accessed June 7, 2011].

SPW-DG04, Patrimoine (Biens classés et Zones de protection). Available at: http://spw.wallonie.be/dgo4/site_thema/index.php [Accessed April 8, 2013].

Swiss Federal Office of Culture, Martin, O. \& Gendre, S. eds., 2010. UNESCO World Heritage: Serial Properties and Nominations.

UNESCO, 1972. Convention Concerning the Protection of the World Cultural and Natural Heritage, Paris: UNESCO.

UNESCO et al., 2011. Preparing World Heritage Nominations Second Edition., UNESCO.

UNESCO, 2012a. Operational Guidelines for the Implementation of the World Heritage Convention. UN Doc WHC. 12/01 July 2012. Available at: http://whc.unesco.org/en/guidelines [Accessed January 2, 2013].

UNESCO, 2012b. Understanding World Heritage in Asia and the Pacific. The Second Cycle of Periodic Reporting 2010-2012, Paris: UNESCO.

UNESCO, 2013. World Heritage List. UNESCO World Heritage Centre. Available at: http://whc.unesco.org/en/list [Accessed April 8, 2013].

Vileikis, O. et al., 2012. Documentation in World Heritage conservation: Towards managing and mitigating change the case studies of Petra and the Silk Roads. Journal of Cultural Heritage Management and Sustainable Development, 2(2), pp.130-152.

VIOE, Inventaris Onroerend Erfgoed. Available at: http://inventaris.vioe.be/ [Accessed November 2, 2010].

Waller, R., 1995. Risk management applied to preventive conservation C. L. Rose, C. A. Hawks, \& H. H. Genoways, eds. Storage of natural history collections: A preventive conservation approach, pp.21-28.

Williams, T., 2011. Silk Roads Thematic Study., Unpublished report: Institute of Archaeology, University College London.

\footnotetext{
${ }^{\mathrm{i}}$ This mechanism was proposed by the Director-General to ensure the proper implementation of the World Heritage Committee decisions (WHC-07/31.COM/5.2).

${ }^{\text {ii } U N E S C O ~ c o n s u l t a t i o n ~ m e e t i n g s ~ f o r ~ t h e ~ S i l k ~ R o a d s ~}$ nomination: Turpan (August 2006, China), Samarkand (October 2006, Uzbekistan), Dushanbe (April 2007, Tajikistan), Xi'an (June 2008, China), Almaty (May 2009, Kazakhstan), Xi' an (November 2009, China), Ashgabat (May 2011, Turkmenistan), and Bishkek (September 2012, Kyrgyzstan).
} 